\author{
Rafael de Lima Pedro ${ }^{1 *}$, Gabriel Maia \\ Krammer ${ }^{2}$, Luise Gomes da Motta ${ }^{3}$ and \\ Marcelo de Castro Costa ${ }^{4}$ \\ ${ }^{1} \mathrm{PhD}$ student of Pediatric Dentistry and Orthodontic \\ Departament of Federal University of Rio de Janeiro- Brazil \\ ${ }^{2}$ Graduated student of Federal Fluminense University-Brazil \\ ${ }^{3}$ Adjunt Professor of Odontotécnica Departamento f Federal \\ Fluminense University - Brazil \\ ${ }^{4}$ Adjunt Professor of Pediatric Dentistry and Orthodontic \\ Departament of Federal University of Rio de Janeiro - Brazil \\ Dates: Received: 22 December, 2015; Accepted: \\ 04 January, 2016; Published: 08 January, 2016 \\ *Corresponding author: Rafael Lima Pedro, Rua \\ Sílvio Fontes, n. 100 bl. 1 ap. 207, Bangu, CEP: \\ 21833-070, Rio de Janeiro, RJ, Brazil, Tel: 055021 \\ 34693551; E-mail: drpedrorafael@gmail.com \\ www.peertechz.com \\ Keywords: Hypersensibility; Dental; Toothpaste; In \\ vitro \\ ISSN: 2394-8418
}

\section{Research Article \\ Effect of Desensitizing Products on the Morphology of Dentin Substrate}

\section{Introduction}

The carious and non-carious cervical lesions form a more complex group in dental practice, mainly referent to the identification of the etiologic agent and to the treatment to be given [1-3]. Normally, in many cases, they present high sensitivity, generating discomfort to the patient.

The etiology of them is, usually, of a multifactor nature, which makes it difficult to diagnose and ultimately treat the resulting dentinal hypersensitivity $(\mathrm{DH})[4,5]$. Due to these characteristics, DH is considered a chronic disorder that manifests itself though acute pain [1], not linked to an actual pathological process. Normally it results from chemical/osmotic and physical mechanical stimuli. However, the stimulus that is most commonly troubling is the ingestion of cold foods or even breathing through the mouth $[2,6]$. An important premise for the study of desensitizing therapies that derives from the hydrodynamics theory is that $\mathrm{DH}$ can be reduced by obliterating the exposed dentinal tubules $[2,6]$.

Among the most used treatments for hypersensitivity we can highlight sodium fluoride [7], which forms a fluoride reservoir on the enamel surface (calcium fluoride), additionally, a small fraction of the fluorides applied on the dentin surface manages to be retained in the insoluble form of fluorapatite and act against sensitivity $[3,4,6]$.

Another substance used is potassium nitrate, with a typically occlusive effect on the dentin $[4,8]$, characterizing two different effects in reducing the dentin hyperesthesia, one immediate and one intermediate. Blockage of the tubules by crystals characterizes the intermediate effect, while the neuronal depolarization characterizes the immediate desensitizing effect of the potassium nitrate [9].
Research suggests that arginine, a natural amino acid found on the saliva, together with calcium carbonate, positively charged at physiological $\mathrm{pH}$, are bound to the dentin surface, negatively charged, and help forming a calcium-rich layer on the dentin surface and within the dentinal tubules, sealing them. The arginine causes the occlusion of the dentinal tubules and, theoretically, such occlusion remains intact even after exposure to acids [10].

Therefore, the purpose of this study was to test, in vitro, the action of several desensitizing materials in bovine dentin, verifying its effectiveness in obliterating the dentinal tubules.

\section{Material and Methods}

The study were laboratorial, in vitro one with convenience sample. The products used were select among the most used by dental sensitivity and the bovine dentin by human similarity.

\section{Material selection}

Three products for professional use with a known desensitizing action have been tested.

Product 1: Dessensibilize KF 2\% - 5\% Potassium nitrate and 2\% sodium fluoride (FGM)

Product 2: Flutop Gel Neutro - 2\% sodium fluoride (SSWhite)

Product 3: Colgate Sensitive Pró-Alívio ${ }^{\circledR}$ Arginine- (8\%) and Calcium carbonate-based toothpaste (Colgate)

\section{Sample preparation and experimentation}

This study used three experimental group and two controls (positive and negative one). The objective were the dentin substrate of the same tooth had be used in all groups to avoid a sample bias, 
for example, regardless of the effectiveness of the product used or not. Thus each tooth serves as control of himself. So, four extracted healthy bovine molars were selected out of which 20 dentin blocks of the cervical region were obtained (one block to same tooth for each group), cut with carborundum disk, refrigerated and their size verified via $\mathrm{Hu}$-Fried $\mathrm{y}^{\circledR}$ millimeter probe, resulting in a $5 \mathrm{x} 5 \mathrm{~mm}$ final area.

To facilitate the product action and after the scanning electron microscope (SEM) evaluation, the dental surface were polishing. The specimens were kept in distilled water throughout the research period and, to facilitate handling, were fixed with photopolymerizable resin in plastic bases with a $3 \mathrm{~cm}$ diameter. The standardized smear was prepared on all specimens using 400-type sandpaper for 1 minute followed by 60014-type sandpaper for the same amount of time and stored separately for 1 week in distilled water until performance of the applications.

To assess the dentin tubules of each group and if them could interfere the final results, two groups were add, a negative control, were no laboratorial experimentation were used and a positive control group were it was used a product to allow the greatest amount of open tubules without use of any other product for close them. To compose the negative control group (group A), four specimens were separated and not submitted to any type of treatment. For the positive control (Group B), after the smear, four blocks were treated with 37\% phosphoric acid for 20 seconds and then washed for the same amount of time for full removal of the smear layer.

The experiment group contained twelve dentin surface blocks divided in 3 groups $(n=4)$ on which different substances were applied. The bull medicine of companies that produce the products were followed for use of all products tested.

On group C $(n=4)$ a gel solution based on Potassium nitrate $5 \%$ and sodium fluoride $2 \%$ was used. The brand used was Desensibilize KF 2\% (FGM). The desensitizing gel was evenly applied on the blocks with the aid of a new and free from infection paintbrush, then, after the minimum 10-minute period had passed, the gel was removed from the specimens with cotton and abundant distillation water.

On group D $(n=4)$ a gel based on sodium fluoride 2\% (Flutop Gel Neutro Cristal - SSWhite) was applied. The fluoridated gel was applied on the specimens and removed with the aid of cotton and abundant distillation water after a 4-minute period.

On group E $(n=4)$ a paste based on Arginine $8 \%$ and calcium carbonate (Sensitive Pró-Alívio ${ }^{\circledR}$ toothpaste - Colgate) was used. The paste was applied with the aid of a Robson brush on low rotation for 10 seconds and then, the excess was removed with a cotton ball and abundant distillation water.

\section{Sample analysis}

The specimens were submitted to oven drying at $37^{\circ} \mathrm{C}$ for 12 hours, mounted on stubs, vacuum metallized with gold ions on a DESK II Deton Vacuum device for 10 minutes, and analyzed on a SEM JEOL JFM no. 5610 L.V., at the IMA laboratory, at the Federal University of Rio de Janeiro.
The photomicrographs were obtained through SEM with a 1000x to $6000 \mathrm{x}$ increase, totaling 120 photomicrographs. The qualitative analysis of the dentinal tubules was made by a second evaluator in order to prevent any knowledge bias. The features on the intertubular and peritubular dentinal surface and the condition of the dentinal tubes were considered, and the quantity and characteristics of the tubules found in the assessed area were analyzed and multiplied by the total area of the sample, reaching an approximate figure of the total number of dentinal tubules present in that sample.

For the quantitative analysis, the statistics program SPSS ${ }^{\circledR} 16.0$ was used through Variance Analysis (ANOVA) tests and Tukey post-test for multiple comparisons, with a $5 \%$ significance. The number and diameters of dentinal tubules were compared across the various groups. The results were analyzed by the team with help of a statistician when necessary.

\section{Results}

The analysis of the number of dentinal tubules presented the following results: Group $A=32,060 \pm 10,360 / \mathrm{mm}^{2}$, Group B $=40,710 \pm 8,255 / \mathrm{mm}^{2}$; Group C $=39,490 \pm 7,375 / \mathrm{mm}^{2}$; Group D $=31,877 \pm 9,527 / \mathrm{mm}^{2}$ and Group $\mathrm{E}=30,297 \pm 10,008 / \mathrm{mm}^{2}$. The differences were considered significant $(\mathrm{p}<0.01)$ when groups $B$ and $C$ were compared to the others (Chart $1 \mathrm{~A})$. The analysis of the diameters of the tubules (Group $\mathrm{A}=1.39 \pm 0.48 \mu \mathrm{m}$; Group $\mathrm{B}=$ $2.34 \pm 0.57 \mu \mathrm{m}$; Group $\mathrm{C}=2.28 \pm 0.51 \mu \mathrm{m}$; Group $\mathrm{D}=1.44 \pm 0.44 \mu \mathrm{m}$ and Group $\mathrm{E}=1.42 \pm 0.45 \mu \mathrm{m})$ showed significant differences $(\mathrm{p}<0.01)$ between groups $\mathrm{B}$ and $\mathrm{C}$ when compared to the other groups (Chart 1B).

The descriptive analysis of the photomicrographs of group A and group B presented most of the tubules open. However, the presence of deposits on the peritubular and intertubular dentin was observed only on group A. Group B presented an absence of smear layer on the sample surface (Figures 1,2).

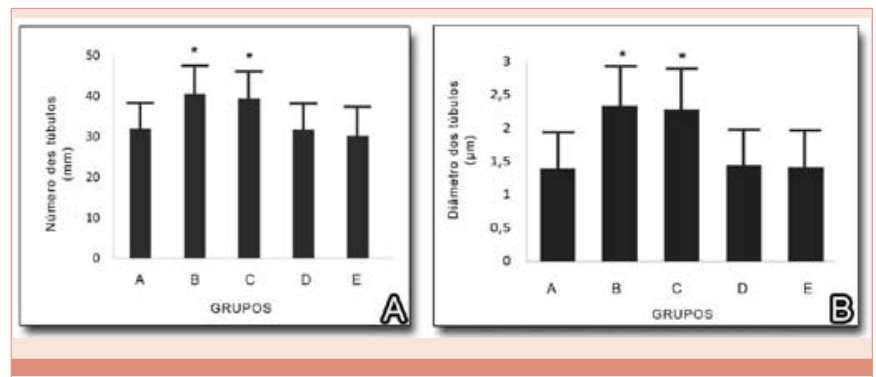

Chart 1: A: Average and standard deviation of the number of dentinal tubules after the treatments. B: Average and standard deviation of the diameter of dentinal tubules after the treatments. ( $\left.{ }^{*}\right)$ significantdifferences with Group B and Group C $(p<0.01$ - ANOVA with Tukey post-test).
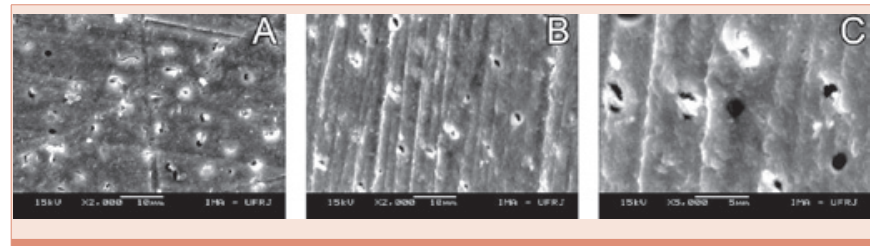

Figure 1: Samples of Group A with an increase of 2000x (A and B) and 5000x (C). 
The samples on Group C (Figure 3) and D (Figure 4) presented open and closed tubules, partially obliterated, deposits on the peritubular and intertubular dentin and a small quantity of smear layer. The specimens on group E (Figure 5), also presented open and partially obliterated tubules, with a small quantity of smear layer. However, when compared to groups $\mathrm{C}$ and $\mathrm{D}$, the samples on Group E had a higher quantity of deposits on the peritubular and intertubular dentin with most tubules closed.

\section{Discussion}

It is well known that, after dental caries, hypersensitivity is one of the greatest complaint of dental care patients [2-4]. In the literature we found an extensive study about this theme; however our study was the first one that our knowledge that quantifies the dentinal tubules closing.

Dentinal hypersensitivity was first described by Brännström and Aström [9], being explained by the physical process called "Hydrodynamics Theory". According to this theory, loss of enamel or cementum in the cervical region favors the exposure of the

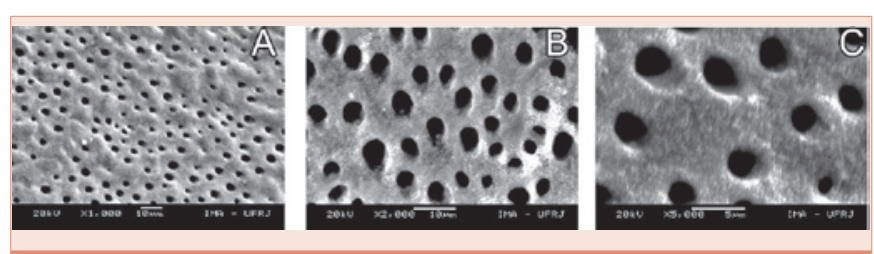

Figure 2: Samples of Group B with an increase of 1000x (A), 2000X (B) and $5000 X(C)$.
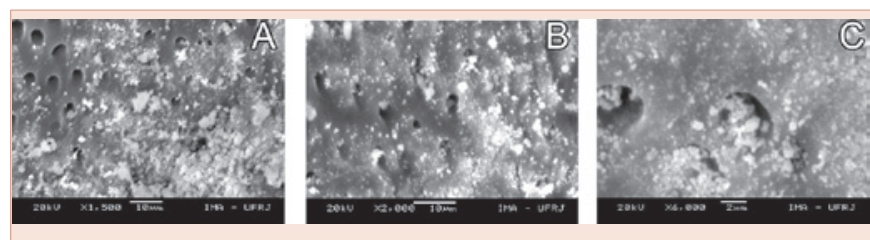

Figure 3: Samples of Group C with an increase of 1500x (A), 2000x (B) and $6000 \times(C)$.
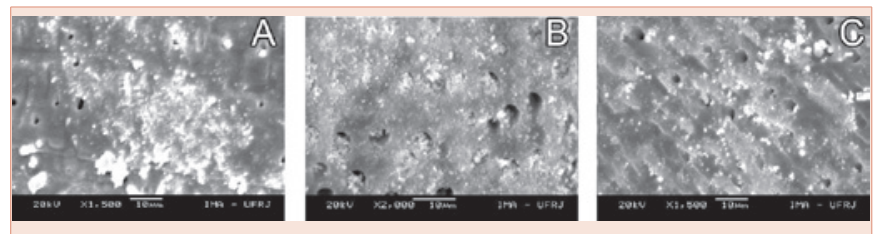

Figure 4: Samples of Group D with an increase of 1500x (A and C) and 2000x (B).
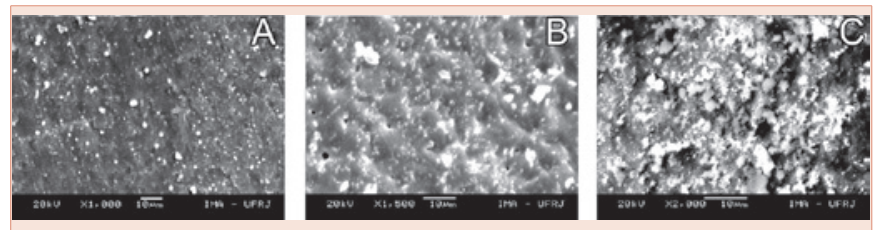

Figure 5: Samples of Group E with an increase of 1000x (A), 1500x (B) and 2000x (C). dentin and, consequently, the dentinal tubules become exposed to the oral environment. Under certain chemical, thermal, tactile and osmotic stimuli, such as more acidic foods an using more abrasive dentifrices for dental bleaching, the dentinal fluid moves inside the tubules indirectly stimulating the pulpal nerve endings, causing the sensation of pain. Nevertheless, the exact mechanism through which the dentinal fluid stimulates the nerve endings and causes pain is still unknown [10].

The treatments for dental sensitivity are varied. They can be more radicals such as restorations of sensitive teeth [11], until more conservative ones, like laser therapy [12], or professional desensitizing products $[1,2,4,5]$. In our study we choose different forms of presentation of those products that related improvement in the sensitivity from the first application for determinate the real changes in dental tubule.

In our study we used bovine teeth as substitutes for human teeth due to facility to obtain them and to their similitude [14], in addition to the fact that bovine teeth have wider dentinal tubules due to an increase in the dentinal permeability resulting from the difference between the deep and superficial dentin on both types of teeth [15]. Since our purpose was precisely to verify the action of desensitizing products on the dentinal tubules, using a substrate in which they are naturally wider proved to be more suitable.

A remarkable factor in our study was to prove that all products tested were effective in their proposal, which was to obliterate at least partially the dentinal tubules and consequently to reduce dentinal hypersensitivity. However, in vivo studies are still required to prove whether these results can be extended to patients that present challenges inherent to the oral system, and whether this relief would be temporary or depend on regular applications.

The product with the best performance was the arginine-based paste, which confirms previous studies [15], despite being slightly more expensive, we were able to notice a full obliteration of the tubules, which consequently would result in a more lasting effect against dentinal hypersensitivity.

Despite several studies research about dentin sensitivity, both dentist and patients has not known all products available and the correct how to use them. Our study showed conservative, not expensive and easy options of products for treatment of this sensitivity.

We had chosen bovine dentin because similarly studies has related of its similarity with human dentin, so analyses the effect in bovine specimen could be a first step for further studies in human, in vitro and in vivo.

Patients who have changes in their dentinal structures such as amelogenesis imperfect [16], fluorosis [17] and hypoplasias [18], have also reported a higher propensity to present dentinal hypersensitivity. Studies in this area, enabling the development of increasingly accessible products, would also favor these patients, for whom even quality of life is affected.

\section{Conclusion}

The samples from group E had a higher quantity of deposits on 
the peritubular and intertubular dentin with most closed tubules. Although, the groups A and B presented more opened dentinal tubules. However, only A has deposited a substratum from the reaction with desensitizing materials on the peritubular and intertubular dentin indicating same closed tubules. The analysis of the diameters of the tubules showed significant differences in groups $\mathrm{B}$ and $\mathrm{C}$ when compared to the other groups.

\section{Acknowledgments}

We are thankful to CNPq for the opportunity to do this research.

\section{References}

1. Sanjay M, Vivek A, Bhoomika A (2010) Dentin hypersensitivity: Recent trends in management. J Conserv Dent 13: 218-224.

2. Holland GR, Narhi MN, Addy M, Gangarosa L, Orchardson R (1997) Guidelines for the design and conduct of clinical trials on dentine hypersensitivity. J Clin Periodontol 24: 808-813.

3. Gillam DG, Seo HS, Newman HN, Bulman JS (2001) Comparison of dentine hypersensitivity in selected occidental and oriental populations. J Oral Rehabil 28: 20-25.

4. Porto IC, AK Andrade, MA Montes (2009) Diagnosis and treatment of dentinal hypersensitivity. J Oral Sci 51: 323-332.

5. Lee WC, WS Eakle (1996) Stress-induced cervical lesions: review of advances in the past 10 years. J Prosthet Dent 75: 487-494.

6. Chabanski MB, DG Gillam (1997) Aetiology, prevalence and clinical features of cervical dentine sensitivity. J Oral Rehabil 24: 15-19.

7. Chidchuangchai W, N Vongsavan, B Matthews (2007) Sensory transduction mechanisms responsible for pain caused by cold stimulation of dentine in man. Arch Oral Biol 52: 154-160.
8. Cummins D (2010) Recent advances in dentin hypersensitivity: clinically proven treatments for instant and lasting sensitivity relief. Am J Dent 3A-13A.

9. Brannstrom M, A Astrom (1972) The hydrodynamics of the dentine; its possible relationship to dentinal pain. Int Dent J 22: 219-227.

10. Pashley DH (1986) Dentin permeability, dentin sensitivity, and treatment through tubule occlusion. J Endod 12: 465-474.

11. Ritter AV, de L Dias W, Miguez P, Caplan DJ, Swift EJ Jr (2006) Treating cervical dentin hypersensitivity with fluoride varnish: a randomized clinical study. J Am Dent Assoc 137: 1013-1020.

12. Aranha AC, C de Paula Eduardo (2012) Effects of Er:YAG and Er,Cr:YSGG lasers on dentine hypersensitivity. Short-term clinical evaluation. Lasers Med Sci 27: 813-818.

13. Reeves GW, Fitchie JG, Hembree JH Jr, Puckett AD (1995) Microleakage of new dentin bonding systems using human and bovine teeth. Oper Dent 20: 230-235.

14. Barrientos C, Xaus G, Leighton C, Martin J, Gordan VV, et al. (2011) Oxalic acid under adhesive restorations as a means to reduce dentin sensitivity: a four-month clinical trial. Oper Dent 36: 126-132.

15. Tagami J, L Tao, DH Pashley (1990) Correlation among dentin depth, permeability, and bond strength of adhesive resins. Dent Mater 6: 45-50.

16. Smith RN, Elcock C, Abdellatif A, Bäckman B, Russell BM, et al. (2009) Enamel defects in extracted and exfoliated teeth from patients with Amelogenesis Imperfecta, measured using the extended enamel defects index and image analysis. Arch Oral Biol 54: 86-92.

17. Tonguc MO, Ozat Y, Sert T, Sonmez Y, Kirzioglu FY (2011) Tooth Sensitivity in Fluorotic Teeth. Eur J Dent 5: 273-280.

18. Gutta KS, Naikmasur VG, Bhargava P, Bathid RJ (2010) Frequency of Developmental Dental Anomalies in the Indian Population. Eur J Dent 4: 263-269.

Copyright: (c) 2016 de Lima Pedro R, et al. This is an open-access article distributed under the terms of the Creative Commons Attribution License, which permits unrestricted use, distribution, and reproduction in any medium, provided the original author and source are credited. 